UDC 347.51

LBC 67.404.219.4

\title{
THE SUBJECTS OF THE OBLIGATION OF REPARATION OF DAMAGE CAUSED BY DEFECTS OF GOODS, WORKS AND SERVICES
}

\author{
Darya N. Davtyan-Davydova \\ Volgograd State University, Volgograd, Russian Federation
}

\begin{abstract}
Introduction: the article is devoted to the identification of problems related to the constituent entities in the obligation to compensate for harm caused by the shortcomings of goods, works and services. Which generally follows from the provisions of paragraph 3 of Chapter 59 of the Civil code of the Russian Federation. Thus on the one hand the subject structure in a certain way depends on another, civil legal relationship preceding it; on the other quite possible discrepancy of a circle of participants of the initial civil legal relationship and the special tort obligation. The purpose of the study is to identify the subject composition of the obligation to compensate for harm caused by the shortcomings of goods, works and services. Applied in the aggregate methods of scientific knowledge, among which the main - methods of induction, deduction, analysis and comparative method. Results: as a rule, the parties to the obligation to compensate are the cause of harm and the victim. However, with regard to the obligation arising from the injury caused by defects in goods, works and services, this constituent entity has some fundamental features.
\end{abstract}

Summary: the existence of a contractual relationship remains a prerequisite for the creation of an obligation. The obligation to compensate is constructed here in such a way that the debtor may be the manufacturer of the goods not bound by contractual obligations with the buyer, and the creditor may be the person who uses the goods but does not acquire them. Special kind of interaction of such subjects of the considered tort obligation as the producer and the seller (in case of causing harm owing to shortcomings of goods), nevertheless does not give the bases to qualify it on model of the obligation with plurality of persons, at least for the reason that any uniform obligation General for both these persons, in this case is absent, and there is only legally fixed alternative in the form of a potential opportunity for the injured party independently to define to whom to address the claims.

Key words: obligation, the consumer, the goods, work or service, buyer, seller, debtor, creditor, delicate undertaking, harm, a civil relationship, defects, damages, contractual obligations.

УДК 347.51

ББК 67.404.219.4

\section{СУБЪЕКТЫ ОБЯЗАТЕЛЬСТВА ПО ВОЗМЕЩЕНИЮ ВРЕДА, ПРИЧИНЕННОГО ВСЛЕДСТВИЕ НЕДОСТАТКОВ ТОВАРОВ, РАБОТ И УСЛУГ}

\author{
Дарья Николаевна Давтян-Давыдова
}

Волгоградский государственный университет, г. Волгоград, Российская Федерация

Введение: статья посвящена выявлению проблем, связанных с субъектным составом в обязательствах по возмещению вреда, причиненного вследствие недостатков товаров, работ и услуг, который в целом вытекает из положений параграфа 3 гл. 59 Гражданского кодекса Российской Федерации (ГК РФ). При этом, с одной стороны, субъектный состав определенным образом зависит от другого, предшествующего ему гражданского правоотношения; с другой - вполне возможно несовпадение круга участников изначального гражданского правоотношения и специального деликтного обязательства. Цель исследования - выявить 
субъектный состав обязательств по возмещения вреда, причиненного вследствие недостатков товаров, работ и услуг. Применены в совокупности методы научного познания, среди которых основные - методы индукции, дедукции, анализа и компаративный метод. Результаты: сторонами обязательства по возмещению вреда, как правило, выступают причинитель вреда и потерпевший. Однако применительно к обязательству, возникающему из причинения вреда недостатками товаров, работ и услуг, этот субъ ектный состав обладает некоторыми принципиальными особенностями.

Выводы: наличие договорного отношения остается необходимым условием возникновения обязательства. Обязательство по возмещению вреда здесь построено таким образом, что на стороне должника может оказаться изготовитель товара, не связанный договорными обязательствами с покупателем, а на стороне кредитора - лицо, пользующееся товаром, но не приобретавшее его.

Особого рода взаимодействие таких субъектов рассматриваемого деликтного обязательства, как производитель и продавец (в случае причинения вреда вследствие недостатков товара), все же не дает оснований квалифицировать его по модели обязательства со множественностью лиц хотя бы по той причине, что какоелибо единое обязательство, общее для обоих этих лиц, в данном случае отсутствует, а имеет место лишь юридически закрепленная альтернатива в виде потенциальной возможности для потерпевшей стороны самостоятельно определить, к кому адресовать свои притязания.

Ключевые слова: обязательство, потребитель, товар, работа или услуга, покупатель, продавец, должник, кредитор, деликатное обязательство, вред, причинение вреда, гражданское правоотношение, недостатки товара, возмещение вреда, договорные обязательства.

\section{Введение}

Субъектный состав обязательства по возмещению вреда, причиненного вследствие недостатков товаров, работ и услуг, в целом вытекает из положений параграфа 3 гл. 59 ГК РФ [3].

Прежде всего обращает на себя внимание то обстоятельство, что этот субъектный состав определенным образом зависит от другого, предшествующего ему гражданского правоотношения; вместе с тем вполне возможно несовпадение круга участников изначального гражданского правоотношения, с одной стороны, и специального деликтного обязательства, с другой.

Сторонами обязательства по возмещению вреда, как правило, выступают причинитель вреда и потерпевший. Однако применительно к обязательству, возникающему из причинения вреда недостатками товаров, работ и услуг, этот субъектный состав обладает некоторыми принципиальными особенностями. В качестве потерпевшего может выступать потребитель товара, работы или услуги. $\mathrm{B}$ соответствии с преамбулой Закона «O защите прав потребителей», признается потребителем исключительно гражданин (физическое лицо). Аналогичная позиция характерна для права ЕС, в котором потребителем может быть только физическое лицо [2]. Однако по ст. 1095 ГК РФ возмещается вред, причи- ненный не только физическому, но и юридическому лицу.

В свою очередь отличительной чертой потребителя является цель приобретения им товаров, работ и услуг. В ст. 13 Брюссельской конвенции по вопросам юрисдикции и принудительного исполнения судебных решений в отношении гражданских и коммерческих споров 1968 г. «потребитель» [1] определялся как лицо, заключающее договор с целью, не связанной с торговлей и его профессией. Аналогичный подход использован в Директиве 2005/ 29/ЕС о недобросовестной коммерческой практике по отношению к потребителям на внутреннем рынке [4]: в качестве потребителя рассматривается любое физическое лицо, которое, вступая в коммерческие отношения, регулируемые настоящей Директивой, преследует свои личные, а не торговые, деловые или профессиональные интересы [6].

\section{Потребитель в обязательствах по возмещению вреда,} причиненного вследствие недостатков товара, работ и услуг

$\mathrm{B}$ соответствии с разъяснениями «О некоторых вопросах, связанных с применением Закона Российской Федерации “О защите прав потребителей”» (утв. приказом ГАК РФ от 20 мая 1998 г. № 160), не является потребителем гражданин, приобретающий товары для 
организаций и за их счет с целью использования этих товаров в производстве, а также заказывающий для организаций за их счет работы, услуги в этих же целях (например, приобретение фотокамеры для работы в издательстве, редакции, химическая чистка штор, натирка полов и т. д.). Однако потребителем является гражданин, пользующийся услугой личного характера, хотя и заказанной для производственных нужд (например, услуга по перевозке, по проживанию в гостинице в командировочных целях).

Схожая позиция высказана в Постановлении Пленума Верховного суда Российской Федерации от 28 июня 2012 г. № 17 «О рассмотрении судами гражданских дел по спорам о защите прав потребителей» (п. 3).

Потерпевшими по данному обязательству в силу закона могут быть как физические лица (при вреде, причиненном их жизни, здоровью или имуществу), так и юридические лица (лишь при вреде, причиненном имуществу).

При этом в абз. 2 ст. 1095 ГК РФ особо подчеркивается, что правила, предусмотренные настоящей статьей, применяются лишь в случаях приобретения товара (выполнения работы, оказания услуги) в потребительских целях, а не для использования в предпринимательской деятельности.

В данном случае, хотя буквальное толкование указанного нормативного положения и указывает на психологический критерий (целеполагание), вполне возможно исходить из презумпции соответствия между целями и использованием, то есть из фактического поведения потребителя.

Если же товары (работы, услуги), повлекшие причинение вреда, использовались в предпринимательских целях, то его возмещение производится по общим правилам гл. 59 ГК РФ.

Вместе с тем в отношении юридического лица возникает неясность по поводу того, что следует считать потреблением, поскольку «потребительские цели гражданина не совпадают с потребительскими целями юридического лица. Для последнего любая эксплуатация, не подпадающая под понятие “использование в предпринимательской деятельности”, должна рассматриваться как ис- пользование в потребительских целях, поскольку определить потребительские цели для юридического лица гораздо труднее, чем эксплуатацию в предпринимательской деятельности» [7].

Таким образом, к потребительским целям юридического лица может быть отнесено использование имущества любым способом, не предполагающим извлечение прибыли. Например, поскольку речь идет о некоммерческих юридических лицах, то в рамках рассматриваемого обязательства может возмещаться вред, причиненный недостатками товаров, работ или услуг, которые были направлены или которые планировалось направить на непосредственное достижение уставных целей юридического лица.

\section{Причинитель вреда в обязательствах по возмещению вреда, \\ причиненного вследствие недостатков товара, работ и услуг}

В качестве причинителя вреда выступают изготовитель и продавец товара, а также исполнитель работы или услуги.

Между тем существуют определенные различия субъектного состава лиц, возмещающих вред, по ГК РФ и по законодательству о защите прав потребителей.

В соответствии с преамбулой Закона «О защите прав потребителей», изготовителями, исполнителями и продавцами, несущими ответственность по данному закону, являются организации независимо от организационно-правовой формы, а также индивидуальные предприниматели. При этом, как отмечается в Постановлении Пленума Верховного суда Российской Федерации от 28 июня 2012 г. № 17 «О рассмотрении судами гражданских дел по спорам о защите прав потребителей» (п. 12), учитывается не только правовой статус предпринимателя, но и фактическое занятие предпринимательской деятельностью.

В действительности, круг субъектов, возмещающих вред в соответствии с нормами параграфа 4 гл. 59 ГК РФ, более широк, поскольку включает в себя всех возможных изготовителей и продавцов товаров, а также исполнителей работ и услуг, каковыми могут быть не только юридические лица и предпри- 
ниматели, но и иные физические лица, в том числе вовсе не занимающиеся предпринимательской деятельностью ни юридически, ни фактически. Иначе говоря, полностью выведены законом за рамки данного обязательства лишь такие субъекты, как государство и муниципальные образования.

Лицо, обязанное возместить вред, в данном случае может именоваться «причинителем вреда» лишь условно. Согласно абз. 2 п. 1 ст. 1064 ГК РФ, обязанность возмещения вреда может быть возложена на лицо, не являющееся причинителем вреда. С нашей точки зрения, именно такой случай имеет место в рамках данного обязательства. Этот исключительный случай возникает, когда вред причинен недостатками товаров и когда лицо, возмещающее вред, определяется по решению потерпевшего независимо от того, чьими деяниями этот вред причинен фактически.

Вариативность рассматриваемого обязательства состоит в том, что в зависимости от оснований его возникновения субъектный состав может определяться в двух различных режимах - в зависимости от того, чем именно был причинен вред.

Если вред причинен вследствие недостатков работы или услуги, то он возмещается лицом, выполнившим работу или оказавшим услугу (исполнителем) (п. 2 ст. 1096 ГК РФ).

Если же речь идет о вреде, причиненном вследствие недостатков товара, то возникают два варианта: вред может возмещаться изготовителем товара или его продавцом. При этом выбор варианта определяется вовсе не тем, кто из них фактически совершил действия или бездействия, обусловившие недостатки товара, а исключительно усмотрением потерпевшего.

В данном случае явно находит свое применение принцип защиты слабой стороны в обязательстве, с тем, чтобы предоставить потерпевшему максимальные гарантии восстановления его прав и интересов, а также упростить ему процедуру возмещения вреда.

\section{Выводы}

Таким образом, основные особенности субъектного состава обязательства по возмещению вреда, причиненного недостатками товаров (работ, услуг) состоят в следующем:
1) юридически предусмотренная и гарантированная возможность несовпадения круга лиц, фактически причинивших вред, с лицами, обязанными его возмещать;

2) использование субъективного признака (целеполагание) в качестве критерия для определения надлежащего кредитора;

3) решающая роль кредитора (потерпевшего) в определении должника как стороны в деликтном обязательстве.

Особого рода взаимодействие таких субъектов рассматриваемого деликтного обязательства, как производитель и продавец (в случае причинения вреда вследствие недостатков товара), все же не дает оснований квалифицировать его по модели обязательства со множественностью лиц хотя бы по той причине, что какое-либо единое обязательство, общее для обоих этих лиц, в данном случае отсутствует, а имеет место лишь юридически закрепленная альтернатива в виде потенциальной возможности для потерпевшей стороны самостоятельно определить, к кому адресовать свои притязания.

\section{СПИСОК ЛИТЕРАТУРЫ}

1. Арабей, Е. А. Правовые аспекты деятельности Европейского Союза в сфере защиты прав потребителей : дис. ... канд. юрид. наук / Арабей Елизавета Андреевна. - М., 2014. - С. 24.

2. Брюссельская конвенция по вопросам юрисдикции и принудительного исполнения судебных решений в отношении гражданских и коммерческих споров (27 сентября1968 г.) (Извлечение) // Вестник Высшего Арбитражного суда РФ. 1999. - 3 марта. - С. 196.

3. Гражданский кодекс Российской Федерации (часть вторая) от 26 янв. 1996 г. № 14-Ф3 (ред. от 05 дек. 2017) // Российская газета. - 2008. - 22 мая.

4. Директива № 2005/29/ЕС Европейского парламента и Совета Европейского Союза «О недобросовестной коммерческой практике по отношению к потребителям на внутреннем рынке» (Принята в г. Страсбурге 11 мая 2005 г.) // NL. - 2005. - 11 июня (№ 149). - С. 22-39.

5. Иншакова, А. О. Задачи межгосударственного цивильного права в сфере наноиндустрии / А. О. Иншакова / Препринт. - Волгоград : Изд-во ВолГУ, 2011.- $32 \mathrm{c}$.

6. Иншакова, А. О. Международное корпоративное право в глобализирующемся экономическом пространстве: (эволюция и перспективы раз- 
вития) / А. О. Иншакова // Саратовская государственная академия права ; науч. консультант д-р юрид. наук, проф. И. В. Архипов ; рец. д-р юрид. наук, проф. П. М. Филиппов. - Саратов ; Волгоград : Изд-во ВолГУ, 2005. -215 c.

7. Товмасян, А. Р. Обязательства по возмещению вреда, причиненного недостатками товара (работы, услуги) : автореф. дис. ... канд. юрид. наук / Товмасян Артак Рубикович. - М., 1999. - С. 18-19.

\section{REFERENCES}

1. Arabey E.A. Pravovye aspekty deyatelnosti Evropeyskogo Soyuza v sfere zashchity prav potrebiteley: dis. ... kand. yurid. nauk [Legal Aspects of the European Union in the Field of Consumer Protection. Cand. jurid. sci. diss.]. Moscow, 2014. 256 p.

2. Bryusselskaya konventsiya po voprosam yurisdiktsii i prinuditelnogo ispolneniya sudebnykh resheniy v otnoshenii grazhdanskikh i kommercheskikh sporov (27 sentyabrya1968 g.) (Izvlechenie) [The Brussels Convention on Jurisdiction and Enforcement of Judgments in Civil and Commercial Disputes (27 September 1968) (Extract)]. Vestnik Vysshego Arbitrazhnogo suda RF, 1999, March 3, p. 196.

3. Grazhdanskiy kodeks Rossiyskoy Federatsii (chast vtoraya) ot 26 yanv. 1996 g. N 14-FZ (red. ot 05 dek. 2017) [The Civil Code of the Russian Federation (Part Two) of January 26, 1996 no. 14-FL (amend. of December 5, 2017)]. Rossiyskaya gazeta, 2008, May 22.

4. Direktiva N 2005/29/ES Evropeyskogo parlamenta i Soveta Evropeyskogo Soyuza «O nedobrosovestnoy kommercheskoy praktike po otnosheniyu k potrebitelyam na vnutrennem rynke» (Prinyata v g. Strasburge 11 maya 2005 g.) [Directive no. 2005/29/ES of the European Parliament and the Council of the European Union "On Unfair Commercial Practices in Relation to Consumers in the Domestic Market" (Adopted in Strasbourg on 11 May 2005)]. $N L$, 2005, June 11 (no. 149), pp. 22-39.

5. Inshakova A.O. Zadachi mezhgosudarstvennogo tsivilnogo prava $v$ sfere nanoindustrii. Preprint [The Tasks of Interstate Civil Law in the Sphere of Nanoindustry. Preprint]. Volgograd, Izd-vo VolGU, 2011.32 p.

6. Inshakova A.O. Mezhdunarodnoe korporativnoe pravo $v$ globaliziruyushchemsya ekonomicheskom prostranstve: (evolyutsiya $i$ perspektivy razvitiya) [International Corporate Law in the Globalizing Economic Space: (Evolution and Development Prospects)]. Saratov; Volgograd, Izd-vo VolGU, 2005.215 p.

7. Tovmasyan A.R. Obyazatelstva po vozmeshcheniyu vreda, prichinennogo nedostatkami tovara (raboty, uslugi): avtoref. dis. ... kand. yurid. nauk [Obligations for Compensation of Damage Caused by Defects in the Goods (Work, Services). Cand. jurid. sci. abs. diss.]. Moscow, 1999. 26 p.

\section{Information about the Author}

Darya N. Davtyan-Davydova, Senior Lecturer, Department of Civil and International Private Law, Volgograd State University, Base Department of the Southern Scientific Center of the Russian Academy of Sciences, Prosp. Universitetsky, 100, 400062 Volgograd, Russian Federation, davdarya@yandex.ru.

\section{Информация об авторе}

Дарья Николаевна Давтян-Давыдова, старший преподаватель кафедры гражданского и международного частного права, Волгоградский государственный университет, базовая кафедра ЮНЦ PAН, просп. Университетский, 100, 400062 г. Волгоград, Российская Федерация, davdarya@yandex.ru. 